\title{
Fontes protéicas vegetais na alimentação da carpa húngara
}

\author{
Plant protein sources on common carp feeding
}

\section{Giovani Taffarel Bergamin IIII Suziane Ghedini Martinelli ${ }^{\text {II }}$ Marco Aurélio Lopes Della Flora ${ }^{\text {II }}$ Fabio de Araújo Pedron ${ }^{\mathrm{III}}$ Leila Picolli da Silva ${ }^{\mathrm{IV}}$ João Radünz Neto ${ }^{\mathrm{IV}}$}

\section{RESUMO}

\begin{abstract}
A substituição parcial da farinha de carne suína por farelos vegetais em dietas para juvenis de carpa húngara (Cyprinus carpio) foi avaliada em cinco dietas experimentais: um controle (farinha de carne suína (FCS) como fonte protéica) e quatro dietas vegetais: farelo de soja (FS), farelo de canola $(F C)$, farelo de girassol ( $F G)$ ou farelo de linhaça $(F L)$, substituindo 50\% da proteína proveniente da FCS. 195 juvenis $(43,4 \pm 0,4 \mathrm{~g})$ foram alimentados duas vezes ao dia (9 e 15 horas) durante 71 dias. Ao final do experimento, maior peso $(205,69 \mathrm{~g})$, ganho em peso $\left(2,29 \mathrm{~g}\right.$ dia $\left.^{-1}\right)$, taxa de crescimento específico $\left(2,2 \%\right.$ dia $\left.^{-1}\right)$ e conversão alimentar $(1,74)$ foram obtidos nas dietas com FCS, seguido dos tratamentos FC e FS que não diferiram entre si. Os peixes alimentados com FCS, $F G$ e FS apresentaram maior gordura corporal. A dieta FL apresentou piores resultados de desempenho, coeficiente de retenção protéica, deposição de proteína e gordura corporal e no filé. Pode-se concluir que a dieta à base de farinha de carne suína proporciona maior crescimento e deposição de proteína em juvenis de carpa húngara, comparada às dietas com farelos vegetais; os parâmetros de carcaça (rendimentos e índices digestivos) não são afetados pelas fontes protéicas da dieta.
\end{abstract}

Palavras-chave: Cyprinus carpio, farelo de canola, farelo de girassol, farelo de linhaça, farelo de soja, farinha de carne suína.

\section{ABSTRACT}

This study was conducted to evaluate the partial replacement of porcine meat meal by plant-protein meals in diets for common carp (Cyprinus carpio). Five experimental diets were evaluated: control (FCS), only porcine meat meal as protein source, and four plant-based diets: soybean meal $(F S)$, canola meal $(F C)$, sunflower meal $(F G)$ or linseed meal $(F L)$ replacing $50 \%$ of protein from porcine meat meal. Juveniles $(195,43.4 \pm 0.4 \mathrm{~g})$ were fed twice daily (9:00 am and 03:00pm) for 71 days. At the end of the trial, the best weight $(205,69 \mathrm{~g})$, weight gain $\left(2,29 \mathrm{~g}\right.$ day $\left.{ }^{-1}\right)$, specific growth rate $(2,2 \%$ day $\left.^{-1}\right)$ and food conversion ratio $(1,74)$ were obtained in FCS, followed by FC and FS, that did not differ among each other. Fish fed FCS, FG and FS showed higher body fat. The FL diet had the worst performance, protein retention coefficient, protein and fat deposition in whole body and fillet. It was concluded that a diet based on porcine meat meal provides higher growth and protein deposition in common carp juveniles, compared to diets with plant-protein meals; carcass parameters (carcass and fillet yield and digestive indices) are not affected by the dietary protein sources.

Key words: Cyprinus carpio, canola meal, sunflower meal, linseed meal, soybean meal, porcine meat meal.

\section{INTRODUÇÃO}

Atualmente, na formulação de dietas para aquicultura, limitado número de ingredientes é utilizado. A farinha de carne é fonte de origem animal com grande potencial para a aquicultura, pelo alto nível de proteína (45-55\%), menor preço, comparada à farinha de peixe, palatabilidade e equilíbrio de aminoácidos essenciais (GODA et al., 2007). Entretanto, variações na composição, alto teor de gordura e matéria mineral dificultam sua utilização em rações.

IEmpresa Brasileira de Pesquisa Agropecuária, Embrapa Pesca e Aquicultura, Palmas, TO, Brasil.

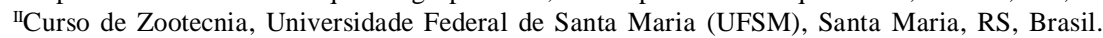

IIIPrograma de Pós-graduação em Zootecnia (PPGZ), Centro de Ciências Rurais (CCR), UFSM, Santa Maria, RS, Brasil.

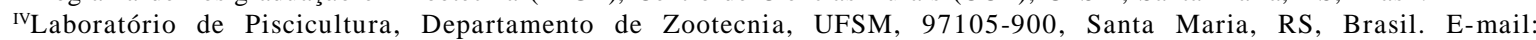
jradunzneto@gmail.com.*Autor para correspondência 
Esses problemas estimulam a procura por ingredientes alternativos com qualidade nutricional equivalente. No Brasil, vários farelos de oleaginosas como soja, canola, girassol e linhaça são produzidos em larga escala, como subprodutos da indústria de óleos, e têm potencial para uso em formulações de dietas para peixes. A composição destes ingredientes é mais constante, entretanto a presença de compostos tóxicos ou inibidores de crescimento e o desbalanço em aminoácidos essenciais podem limitar sua inclusão em rações para a carpa húngara (HASAN et al., 1997). Como alternativa, tem-se utilizado a combinação de fontes vegetais de diferentes origens aliada à suplementação com aminoácidos livres, a fim de se obter rações com qualidade protéica equivalente àquela obtida a partir das fontes de origem animal (SOLTAN et al., 2008).

A carpa húngara (Cyprinus carpio) é utilizada em sistema de produção semi-intensivo a baixo custo, baseado no aproveitamento de resíduos agroindustriais em sua alimentação (TAMASSIA et al., 2004). Porém, o êxito na produção final depende do manejo alimentar empregado nas fases iniciais (alevinagem), nas quais se faz necessário o uso de rações balanceadas que possibilitem o máximo aproveitamento de nutrientes. Assim, o objetivo geral deste trabalho foi avaliar o efeito de diferentes fontes protéicas de origem vegetal em substituição à farinha de carne suína na dieta, sobre o desempenho e a qualidade de carcaça de juvenis de carpa húngara.

\section{MATERIAL E MÉTODOS}

O trabalho foi conduzido no Laboratório de Piscicultura da Universidade Federal de Santa Maria (altitude $95 \mathrm{~m}, 29^{\circ} 43^{\prime} \mathrm{S}, 53^{\circ} 42^{\prime} \mathrm{W}$ ), entre os meses de setembro e dezembro de 2007 (71 dias). Foi utilizado sistema fechado de recirculação de água com 15 unidades experimentais (caixas de polietileno de 310L), abastecidas com água de poço artesiano, na vazão de $2 \mathrm{~L} \mathrm{~min}{ }^{-1}$. O sistema permitia controle da temperatura da água através de resistências elétricas e termostatos. $\mathrm{O}$ controle dos resíduos nitrogenados era feito com o uso de filtro biológico. A temperatura da água foi monitorada diariamente com termômetro de bulbo de mercúrio, e os demais parâmetros (oxigênio dissolvido, $\mathrm{pH}$, amônia, nitrito e alcalinidade) foram monitorados duas vezes por semana, com oxímetro digital (marca YSI, modelo $550 \mathrm{~A}$ ) e kit colorimétrico comercial (Alfakit ${ }^{\circledR}$, Florianópolis - SC, Brasil).

Antes do início do experimento, 210 juvenis de carpa húngara foram selecionados por tamanho e distribuídos nas unidades experimentais, onde permaneceram em adaptação por 14 dias, recebendo ração peletizada ( $32 \%$ de proteína bruta) confeccionada no próprio laboratório. Para o início do experimento, os animais foram pesados (peso médio $43,4 \pm 0,4 \mathrm{~g}$ ) e distribuídos nas respectivas unidades (13 peixes caixa ${ }^{-1}$ ), sendo 15 animais abatidos para obtenção dos valores iniciais de rendimentos e composição centesimal do peixe inteiro e do filé.

O delineamento experimental foi o inteiramente casualizado, com cinco tratamentos e três repetições. Os tratamentos corresponderam às cinco dietas experimentais (Tabela 1): FCS: tratamento controle, tendo a farinha de carne suína como base protéica; FC: farinha de carne + farelo de canola; FG: farinha de carne + farelo de girassol; FL: farinha de carne + farelo de linhaça e FS: farinha de carne + farelo de soja. Os farelos vegetais substituíram 50\% da proteína da farinha de carne suína. As rações foram peletizadas ( $3 \mathrm{a} 8 \mathrm{~mm})$, mantidas em freezer $\left(-18^{\circ} \mathrm{C}\right) \mathrm{e}$ analisadas quanto à composição centesimal (Tabela 2). Os peixes foram alimentados com $5 \%$ do peso vivo em ração, dividida em duas refeições diárias (9 e 15 horas). Uma hora após cada alimentação, as fezes e sobras de ração foram removidas por sifonagem. A quantidade de ração fornecida foi ajustada ( $5 \%$ do peso vivo) a cada 20 dias, por pesagem individual dos animais.

Ao final dos 71 dias experimentais, após jejum de 24 horas, os peixes foram anestesiados com tri-fenoxietanol $(0,03 \%)$ e pesados em balança digital. Foram calculados: peso médio (g), taxa de crescimento específico (\%/dia), conversão alimentar aparente, ganho de peso diário $\left(\mathrm{g} \mathrm{dia}^{-1}\right)$ e ganho em peso relativo (\% do peso inicial). Nove animais por tratamento foram abatidos por hipotermia (água + gelo na proporção 1:1), eviscerados e filetados para obterem-se os valores de rendimento de carcaça e filé (\% do peso inteiro). A coleta de sangue foi realizada em três peixes por tratamento, na veia caudal. Hemoglobina, glicose, triglicerídeos, proteínas totais e colesterol total foram mensurados por espectrofotometria com kits bioquímicos comerciais (Doles ${ }^{\circledR}$, Goiânia - GO, Brasil).

A composição centesimal do peixe inteiro foi determinada em três peixes por tratamento, abatidos por hipotermia. Para composição centesimal do filé, foram utilizadas as amostras retiradas após o cálculo dos rendimentos. A umidade foi determinada pela perda de peso da amostra após 48 horas a $60^{\circ} \mathrm{C}$ em estufa com circulação forçada de ar, seguida de 8 horas a $105^{\circ} \mathrm{C}$. O conteúdo de cinzas foi determinado por queima em forno mufla $\left(550^{\circ} \mathrm{C}\right)$, a proteína bruta $(\mathrm{Nx} 6,25)$ pelo método de microKjeldahl e a gordura foi quantificada seguindo o método de BLIGH \& DYER (1959). As 
Tabela 1 - Composição das dietas (\%).

\begin{tabular}{|c|c|c|c|c|c|}
\hline \multirow{2}{*}{ Ingredientes } & \multicolumn{5}{|c|}{ - } \\
\hline & FCS & $\mathrm{FC}$ & FG & FL & FS \\
\hline Farinha de carne suína & 52,00 & 26,00 & 26,00 & 26,00 & 26,00 \\
\hline Farelo de soja & - & - & - & - & 29,45 \\
\hline Farelo de canola & - & 31,45 & - & - & - \\
\hline Farelo de linhaça & - & - & - & 46,28 & - \\
\hline Farelo de girassol & - & - & 29,75 & - & - \\
\hline Farelo de trigo & 35,99 & 29,44 & 30,74 & 16,61 & 32,54 \\
\hline Milho moído (grãos) & 5,00 & 6,00 & 6,50 & 4,00 & 5,00 \\
\hline Óleo de soja & 2,00 & 2,10 & 2,00 & 2,10 & 2,00 \\
\hline Componentes constantes ${ }^{2,3,4}$ & 5,00 & 5,00 & 5,00 & 5,00 & 5,00 \\
\hline L-Lisina & 0,205 & 0,373 & 0,294 & 0,243 & 0,062 \\
\hline DL-Metionina & 0,406 & 0,411 & 0,418 & 0,462 & 0,443 \\
\hline L-Treonina & 0,172 & 0,169 & 0,126 & 0,276 & 0,070 \\
\hline
\end{tabular}

${ }^{1}$ Tratamentos: FCS: farinha de carne suína; FC: farinha de carne suína + farelo de canola; FG: farinha de carne suína + farelo de girassol; FL: farinha de carne suína + farelo de linhaça; FS: farinha de carne suína + farelo de soja.

${ }^{2}$ Componentes constantes: $1 \%$ de cloreto de colina $(50 \%)+1 \%$ mistura vitamínica $+1 \%$ mistura mineral $+1 \%$ fosfato bicálcico $+1 \%$ cloreto de sódio.

${ }^{3}$ Composição da mistura vitamínica (por kg de produto/MigPlus ${ }^{\circledR}$ ): ác. fólico $3 \mathrm{~g}$; ác. Nicotínico 60g; ác. Pantotênico 30g; Biotina 100mg; Vit.A 10.000.000UI; Vit. B1 8g; Vit. B2 10g; Vit. B6 8g; Vit. B12 20mg; Vit. C 150g; Vit. D3 2.000.000UI; Vit. E 150g; Vit. K3 6g; Inositol 88g.

${ }^{4}$ Composição da mistura mineral (por kg de produto/MigPlus ${ }^{\circledR}$ ): Ferro 30g; Manganês: 5g; Cobre 2g; Zinco 20g; Iodo 900mg; Cobalto 20mg; Selênio $100 \mathrm{mg}$.

Tabela 2 - Composição centesimal e aminoácidos das dietas.

\begin{tabular}{|c|c|c|c|c|c|}
\hline \multirow{2}{*}{ Composição (\%) } & \multicolumn{5}{|c|}{$\begin{array}{l}1 \\
\end{array}$} \\
\hline & FCS & FC & FG & FL & FS \\
\hline Proteína bruta ${ }^{2}$ & 34,85 & 35,01 & 34,67 & 32,30 & 36,25 \\
\hline Extrato etéreo $^{2}$ & 13,63 & 9,76 & 10,16 & 11,81 & 11,81 \\
\hline Matéria mineral $^{2}$ & 15,65 & 12,10 & 12,90 & 12,29 & 12,19 \\
\hline Fibra em detergente neutro ${ }^{2}$ & 17,81 & 18,96 & 16,09 & 16,85 & 14,60 \\
\hline Extrativo não-nitrogenado ${ }^{2}$ & 12,51 & 17,61 & 19,35 & 21,11 & 19,80 \\
\hline Lisina $^{3}$ & 2,20 & 2,20 & 2,20 & 2,20 & 2,20 \\
\hline Metionina $^{3}$ & 0,80 & 0,80 & 0,80 & 0,80 & 0,80 \\
\hline Treonina $^{3}$ & 1,50 & 1,50 & 1,50 & 1,50 & 1,50 \\
\hline Triptofano $^{3}$ & 0,28 & 0,35 & 0,33 & 0,36 & 0,37 \\
\hline Valina $^{3}$ & 1,34 & 1,43 & 1,38 & 1,36 & 1,44 \\
\hline Isoleucina $^{3}$ & 0,90 & 1,04 & 1,02 & 1,00 & 1,15 \\
\hline Leucina $^{3}$ & 1,92 & 1,93 & 1,90 & 1,74 & 2,10 \\
\hline Fenilalanina $^{3}$ & 1,06 & 1,15 & 1,12 & 1,29 & 1,30 \\
\hline Histidina $^{3}$ & 0,64 & 0,65 & 0,68 & 0,66 & 0,72 \\
\hline Arginina $^{3}$ & 2,06 & 2,11 & 1,90 & 2,11 & 2,11 \\
\hline Cálcio $^{3}$ & 3,24 & 2,02 & 1,88 & 1,95 & 1,88 \\
\hline Fósforo $^{3}$ & 1,98 & 1,49 & 1,47 & 1,36 & 1,32 \\
\hline Energia digestível $\left(\mathrm{kcal} \mathrm{kg}^{-1}\right)^{4}$ & 3.099 & 2.906 & 2.905 & 2.903 & 2.997 \\
\hline
\end{tabular}

${ }^{1}$ Tratamentos: FCS: farinha de carne suína; FC: farinha de carne suína + farelo de canola; FG: farinha de carne suína + farelo de girassol; FL: farinha de carne suína + farelo de linhaça; FS: farinha de carne suína + farelo de soja.

${ }^{2}$ Analisada - Laboratório de Bromatologia e Nutrição de Ruminantes - DZ/UFSM.

${ }^{3}$ Calculado a partir de análise dos ingredientes.

${ }^{4}$ Calculada: $\mathrm{ED}=((\mathrm{PB} * 5,64 * 0,75)+(\mathrm{EE} * 9,44 * 0,9)+(\mathrm{ENN} * 4,11 * 0,75))$. 
análises foram realizadas no Núcleo Integrado de Desenvolvimento de Análises Laboratoriais (NIDAL) da UFSM. A partir das composições, foi calculada a retenção de nutrientes: coeficiente de retenção protéica (\%), deposição de proteína corporal (g), deposição de gordura corporal (g), deposição de proteína no filé $(\mathrm{g})$ e deposição de gordura no filé $(\mathrm{g})$.

Todos os dados coletados foram submetidos a teste de normalidade e análise de variância de uma via, em nível de 5\% de significância. As médias foram comparadas pelo teste de Tukey.

\section{RESULTADOS E DISCUSSÃO}

Os parâmetros de qualidade da água mantiveram-se dentro dos limites aceitáveis para criação de peixes de água doce (POLI \& ARANA, 2003): temperatura $23,3 \pm 2,4^{\circ} \mathrm{C}$, oxigênio dissolvido $5,3 \pm 0,8 \mathrm{mg}$ $\mathrm{L}^{-1}, \mathrm{pH} 6,5 \pm 0,0$, alcalinidade $28,2 \pm 6,0 \mathrm{mg} \mathrm{L}^{-1}$, amônia $0,2 \pm 0,1 \mathrm{mg} \mathrm{L}^{-1}$ e nitrito $0,03 \pm 0,06 \mathrm{mg} \mathrm{L}^{-1}$.

Ao final do experimento, foram observadas diferenças significativas para todos os parâmetros de crescimento (peso, TCE, GPD, GPR e CAA), sendo que a dieta FCS apresentou os melhores resultados (Tabela 3), seguida pelos peixes alimentados com FS e FC, que não diferiram entre si. Avaliando o desempenho e a excreção de fósforo e nitrogênio pela carpa comum, JAHAN et al. (2003) verificaram que a taxa de eficiência protéica não diferiu entre as dietas (farinha de penas, farinha de carne ou concentrado protéico de soja), porém a farinha de carne apresentou maior peso final e ganho de peso, enquanto as demais dietas proporcionaram desempenho similar entre si. KIM et al. (1997) substituíram até 75\% da proteína proveniente da farinha de peixe por farelo de soja ou soja integral tostada para juvenis de Cyprinus carpio sem prejudicar o crescimento. Essas informações divergem dos resultados obtidos no presente trabalho com carpa húngara, no qual a substituição de $50 \%$ da proteína proveniente da farinha de carne levou a baixos índices de desempenho. Esses e outros resultados controversos mostram que a eficiência de utilização de fontes protéicas alternativas de origem vegetal pode mudar consideravelmente, de acordo com o tipo e a qualidade do farelo incorporado nas dietas. Provavelmente, a impossibilidade de utilização de maiores níveis de inclusão de fontes vegetais esteja relacionada à presença de fibra, fatores antinutricionais e baixa palatabilidade, que podem diminuir a ingestão e aproveitamento dos alimentos pelos peixes (LUO et al., 2006).

Trabalhos com tilápia nilótica (Oreochromis niloticus) (GAIOTTO et al., 2004) e com juvenis de bagre do canal (Ictalurus punctatus) (WEBSTER et al., 1997) mostram que pode ser utilizado 24 e $36 \%$ de farelo de canola na dieta, respectivamente, para essas

Tabela 3 - Parâmetros zootécnicos dos juvenis de carpa húngara alimentados com diferentes fontes protéicas na dieta.

\begin{tabular}{|c|c|c|c|c|c|c|}
\hline \multirow{3}{*}{ Variáveis $^{1}$} & \multicolumn{5}{|c|}{ 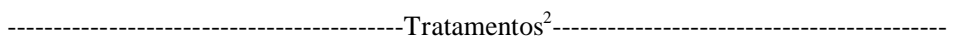 } & \multirow{3}{*}{$\mathrm{CV}^{3}$} \\
\hline & & & & & & \\
\hline & FCS & FC & FG & FL & FS & \\
\hline Peso $(\mathrm{g})$ & $205,69^{\mathrm{a}}$ & $155,47^{\mathrm{b}}$ & $151,75^{\mathrm{b}}$ & $106,05^{\mathrm{c}}$ & $165,12^{\mathrm{b}}$ & 4,31 \\
\hline $\operatorname{TCE}\left(\% \mathrm{dia}^{-1}\right)$ & $2,20^{\mathrm{a}}$ & $1,80^{\mathrm{bc}}$ & $1,74^{\mathrm{c}}$ & $1,27^{\mathrm{d}}$ & $1,88^{\mathrm{b}}$ & 2,55 \\
\hline $\operatorname{GPD}\left(\mathrm{g} \mathrm{dia}^{-1}\right)$ & $2,29^{\mathrm{a}}$ & $1,58^{\mathrm{b}}$ & $1,51^{\mathrm{b}}$ & $0,89^{\mathrm{c}}$ & $1,71^{\mathrm{b}}$ & 5,09 \\
\hline GPR $(\%)$ & $377,84^{\mathrm{a}}$ & $257,52^{\mathrm{bc}}$ & $243,36^{\mathrm{c}}$ & $146,54^{\mathrm{d}}$ & $281,83^{\mathrm{b}}$ & 4,56 \\
\hline CAA & $1,74^{\mathrm{a}}$ & $2,27^{\mathrm{bc}}$ & $2,33^{\mathrm{c}}$ & $3,28^{\mathrm{d}}$ & $2,10^{\mathrm{b}}$ & 3,41 \\
\hline $\mathrm{RC}(\%)$ & 83,26 & 84,31 & 84,07 & 83,90 & 85,59 & 1,17 \\
\hline $\mathrm{RF}(\%)$ & 33,10 & 33,01 & 31,21 & 30,80 & 33,15 & 3,71 \\
\hline $\operatorname{IGV}(\%)$ & 0,50 & 0,91 & 0,82 & 0,34 & 0,62 & 44,01 \\
\hline PROT $\left(\mathrm{g} \mathrm{dL}^{-1}\right)$ & 3,10 & 3,00 & 3,24 & 3,11 & 2,99 & 10,62 \\
\hline $\mathrm{TG}\left(\mathrm{mg} \mathrm{dL}^{-1}\right)$ & 246,34 & 287,11 & 228,69 & 201,05 & 157,03 & 31,74 \\
\hline $\operatorname{COL}\left(\mathrm{mg} \mathrm{dL}^{-1}\right)$ & $116,26^{\mathrm{ab}}$ & $117,98^{\mathrm{ab}}$ & $103,23^{\mathrm{ab}}$ & $124,85^{\mathrm{a}}$ & $89,29^{\mathrm{b}}$ & 11,76 \\
\hline $\operatorname{GLIC}\left(\mathrm{g} \mathrm{dL}^{-1}\right)$ & 84,33 & 76,33 & 64,67 & 61,67 & 64,00 & 17,10 \\
\hline $\mathrm{HB}\left(\mathrm{g} \mathrm{dL}^{-1}\right)$ & 4,98 & 4,68 & 5,62 & 5,21 & 4,14 & 15,88 \\
\hline
\end{tabular}

Médias seguidas de letras diferentes diferem estatisticamente pelo teste de Tukey $(\mathrm{P}<0,05)$.

${ }^{1}$ Variáveis: CT: comprimento total; CP: comprimento padrão; AD: altura dorsal; TCE: taxa de crescimento específico; GPD: ganho em peso diário; GPR: ganho em peso relativo; FC: fator de condição; CAA: conversão alimentar aparente. RC: rendimento de carcaça; RF: rendimento de filé; IGV: gordura visceral; PROT: proteína; TG: triglicerídeos; COL: colesterol; GLIC: glicose; HB: hemoglobina.

${ }^{2}$ Tratamentos: FCS: farinha de carne suína; FC: farinha de carne suína + farelo de canola; FG: farinha de carne suína + farelo de girassol; FL: farinha de carne suína + farelo de linhaça; FS: farinha de carne suína + farelo de soja.

${ }^{3}$ Coeficiente de variação (\%). 
espécies, sem afetar o desempenho dos animais. No presente trabalho, a inclusão de $31,4 \%$ de farelo de canola diminuiu o crescimento das carpas húngaras em comparação à dieta controle (FCS).

A inclusão de 29,7\% de farelo de girassol na dieta das carpas húngaras deste trabalho não trouxe bons resultados. Para tilápia (Tilapia rendalli), o farelo de girassol pode ser incluído até $20 \%$ na dieta (sem a suplementação de aminoácidos), sem prejudicar o crescimento (OLVERA-NOVOA et al., 2002). Trabalhando com truta arco-íris (Oncorhynchus mykiss), SANZ et al. (1994) constataram que o farelo de girassol pode substituir $40 \%$ da proteína proveniente da farinha de peixe sem comprometer o crescimento e ainda reduzindo o custo da dieta, tornando-a mais competitiva comercialmente. Os autores comentam que para a utilização de maiores níveis de farelo de girassol são necessárias tecnologias que levem ao melhor aproveitamento dos nutrientes desta fonte, tanto da proteína quanto dos carboidratos.

Para a manutenção do nível de proteína equilibrado entre as dietas do presente experimento, foi necessária a inclusão de 46,3\% de farelo de linhaça na dieta FL (Tabela 1). Este nível de inclusão supera o máximo recomendado $(25 \%)$ para larvas de carpa comum (HASAN et al., 1997) e pode explicar o pior desempenho dos peixes submetidos a esse alimento.
Outro fato que pode auxiliar na explicação dos resultados é a presença de mucilagem no farelo de linhaça, que pode aumentar o tempo de permanência do alimento no trato digestório, diminuir a ingestão de alimento via sinais de saciedade, além de possuir grande capacidade de ligação com a água, aumentando a viscosidade intestinal e diminuindo a digestibilidade de nutrientes (SOLTAN et al., 2008).

Para os parâmetros metabólicos no sangue (Tabela 3), os peixes alimentados com FL apresentaram maior nível de colesterol que o FS. Avaliando farelos vegetais em substituição à farinha de peixe para juvenis de bacalhau do Atlântico (Gadus morhua), HANSEN et al. (2007) observaram que os peixes alimentados com farelos vegetais apresentaram menor colesterol circulante que os alimentados com farinha de peixe, devido principalmente à fibra e aos polissacarídeos não-amiláceos presentes nos farelos vegetais. $\mathrm{O}$ aumento da fibra reduz a formação de micelas no intestino e os polissacarídeos não amiláceos se ligam aos sais biliares impedindo a absorção das gorduras, resultando em maior excreção de colesterol nas fezes e consequentemente menor colesterol circulante (KRÖGDAHL et al., 2005).

A composição do peixe inteiro (Tabela 4) foi significativamente afetada pelas dietas. Os peixes

Tabela 4 - Composição centesimal do peixe inteiro e filé e deposição de nutrientes dos juvenis de carpa húngara alimentados com diferentes fontes protéicas na dieta.

\begin{tabular}{|c|c|c|c|c|c|c|}
\hline \multirow{2}{*}{ Variáveis $^{1}$} & \multicolumn{5}{|c|}{- Tratamentos ${ }^{2}-$} & \multirow{2}{*}{$\mathrm{CV}^{3}$} \\
\hline & FCS & FC & FG & FL & FS & \\
\hline \multicolumn{7}{|c|}{ 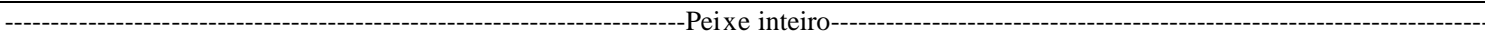 } \\
\hline Umidade $(\%)$ & 71,89 & 71,31 & 72,59 & 72,28 & 71,24 & 1,75 \\
\hline Cinzas $(\%)$ & 1,93 & 2,06 & 1,87 & 2,37 & 2,09 & 10,73 \\
\hline Gordura (\%) & $12,54^{\mathrm{a}}$ & $10,53^{\mathrm{b}}$ & $11,48^{\mathrm{ab}}$ & $10,27^{\mathrm{b}}$ & $13,05^{\mathrm{a}}$ & 5,78 \\
\hline Proteína (\%) & $16,55^{\mathrm{a}}$ & $15,52^{\mathrm{ab}}$ & $15,37^{\mathrm{ab}}$ & $14,60^{\mathrm{ab}}$ & $13,60^{\mathrm{b}}$ & 5,96 \\
\hline $\operatorname{CRP}(\%)$ & $2,17^{\mathrm{a}}$ & $1,54^{\mathrm{b}}$ & $1,50^{\mathrm{b}}$ & $1,07^{\mathrm{c}}$ & $1,35^{\mathrm{bc}}$ & 10,22 \\
\hline $\mathrm{DPC}(\mathrm{g})$ & $27,63^{\mathrm{a}}$ & $18,12^{\mathrm{b}}$ & $17,35^{\mathrm{b}}$ & $9,59^{\mathrm{c}}$ & $16,83^{\mathrm{b}}$ & 13,31 \\
\hline DGC (g) & $24,15^{\mathrm{a}}$ & $15,34^{\mathrm{c}}$ & $16,56^{\mathrm{bc}}$ & $9,99^{d}$ & $21,00^{\mathrm{ab}}$ & 10,24 \\
\hline Umidade $(\%)$ & 78,00 & 77,43 & 77,13 & 78,81 & 78,03 & 1,01 \\
\hline Cinzas (\%) & 0,89 & 0,98 & 0,92 & 0,95 & 1,06 & 9,47 \\
\hline Gordura (\%) & $4,72^{\mathrm{ab}}$ & $5,03^{\mathrm{ab}}$ & $5,54^{\mathrm{a}}$ & $3,43^{\mathrm{b}}$ & $4,81^{\mathrm{ab}}$ & 15,69 \\
\hline Proteína (\%) & 16,74 & 16,43 & 17,36 & 17,32 & 17,18 & 3,39 \\
\hline $\mathrm{DPF}(\mathrm{g})$ & $26,89^{a}$ & $18,46^{\mathrm{b}}$ & $19,30^{\mathrm{b}}$ & $11,51^{\mathrm{c}}$ & $21,85^{\mathrm{b}}$ & 7,27 \\
\hline DGF (g) & $8,77^{\mathrm{a}}$ & $7,04^{\mathrm{a}}$ & $7,72^{\mathrm{a}}$ & $2,83^{\mathrm{b}}$ & $7,25^{\mathrm{a}}$ & 21,95 \\
\hline
\end{tabular}

Médias seguidas de letras diferentes diferem estatisticamente pelo teste de Tukey $(\mathrm{P}<0,05)$

${ }^{1}$ Variáveis: CRP: coeficiente de retenção protéica; DPC: deposição de proteína corporal; DGC: deposição de gordura corporal; DPF: deposição de proteína no filé; DGF: deposição de gordura no filé.

${ }^{2}$ Tratamentos: FCS: farinha de carne suína; FC: farinha de carne suína + farelo de canola; FG: farinha de carne suína + farelo de girassol; FL: farinha de carne suína + farelo de linhaça; FS: farinha de carne suína + farelo de soja.

${ }^{3}$ Coeficiente de variação $(\%)$. 
alimentados com a dieta FCS apresentaram maior teor de gordura em comparação a FC e FL e maior teor de proteína em relação à FS. Além disso, a dieta com FCS apresentou maior coeficiente de retenção protéica e deposição de proteína e gordura corporal. Quanto ao filé, o maior teor de gordura foi nos peixes que receberam a dieta FG em comparação ao FL, que por sua vez resultou nas menores deposições de proteína e gordura no filé. Resultados semelhantes a este trabalho foram observados por JAHAN et al. (2003), que avaliaram farinha de penas, farinha de carne ou farelo de soja na alimentação de carpa húngara. HASAN et al. (1997) observaram diferenças significativas entre as dietas para proteína, lipídio e umidade de pós-larvas de carpa comum alimentadas com ingredientes vegetais, mas atribuíram as diferenças às grandes variações observadas entre e intra-tratamentos, e não propriamente ao efeito da dieta.

A quantidade de gordura depositada nos juvenis de carpa húngara alimentados com a dieta controle (Tabela 4) pode ter sido uma resposta à composição das dietas, uma vez que o teor de extrato etéreo da dieta FCS foi superior aos demais (Tabela 2). Da mesma forma, NANDEESHA et al. (2002) afirmam que o maior teor de gordura dos alevinos de carpa comum alimentados com dieta à base de farinha de peixe, em comparação aos farelos vegetais, é relacionado à maior concentração de gordura desse ingrediente.

Observando os resultados obtidos com juvenis de carpa húngara, é possível concluir que a substituição da farinha de carne por farelos de origem vegetal não se mostrou adequada. Se por um lado os ingredientes protéicos de origem vegetal apresentam valor nutricional elevado, caracterizando-os como potenciais alternativas às fontes de origem animal, por outro, podem possuir fatores antinutricionais ou compostos tóxicos para os peixes. Nesse sentido, a obtenção de informações detalhadas a respeito da composição química dessas fontes é de extrema importância, visando a maximizar a utilização destes ingredientes em dietas para peixes.

\section{CONCLUSÃO}

A dieta somente com proteína de origem animal (FCS) melhora o crescimento e deposição de proteína em juvenis de carpa húngara, comparada às dietas com farelos vegetais. Características de carcaça e filé e metabólitos sanguíneos são pouco afetados pelas fontes protéicas da dieta.

\section{REFERÊNCIAS}

BLIGH, E.G.; DYER, W.J. A rapid method of total lipid extraction and purification. Canadian Journal of Biochemistry and Physiology, v.37, n.8, p.911-917, 1959.

GAIOTTO, J.R. et al. Farelo de canola para juvenis de tilápia do Nilo (Oreochromis niloticus), linhagem Chitralada. Acta Scientiarum Animal Sciences, v.26, n.1, p.15-19, 2004. Disponível em: <http://www.periodicos.uem.br/ojs/index.php/ ActaSciAnimSci/article/view/1896>. Acesso em: 20 nov. 2008. doi: $10.4025 /$ actascianimsci.v26i1.1896.

GODA, A.M. et al. Effect of totally or partially replacing fish meal by alternative protein sources on growth of African catfish Clarias gariepinus (Burchell, 1822) reared in concrete tanks. Aquaculture Research, v.38, n.3, p.279-287, 2007. Disponível em: <http://onlinelibrary.wiley.com/doi/10.1111/ j.1365-2109.2007.01663.x/full>. Acesso em: 23 nov. 2008. doi: $10.1111 / \mathrm{j} .1365-2109.2007 .01663 . x$.

HANSEN, A.C. et al. Dietary plant protein utilization in Atlantic cod, Gadus morhua L. Aquaculture Nutrition, v.13, n.3, p.200215, 2007. Disponível em: <http://www3.interscience.wiley.com/ journal/117991418/abstract>. Acesso em: 21 nov. 2008. doi: 10.1111/j.1365-2095.2007.00486.x.

HASAN, M.R. et al. Evaluation of some plant ingredients as dietary protein sources for common carp (Cyprinus carpio L.) fry. Aquaculture, v.151, n.1-4, p.55-70, 1997. Disponível em: <http:/ / w w w. s c i e $\mathrm{n} c$ e d i r e c t . c o m / science $?$ ob $=$ ArticleURL\&udi=B 6T 4D 3 RH 6 WPV $8 \&$ user $=687358 \& \mathrm{rdoc}=1 \& \mathrm{fmt}=\&$ or $i \mathrm{~g}=$ se $\operatorname{arch} \&$ sort $=\mathrm{d} \& \mathrm{v}$ iew $=\mathrm{c} \&$ acct $=\mathrm{C} 000037899 \&$ version $=1 \&$ urlVersion $=0 \&$ useri $\mathrm{d}=687358 \& \mathrm{md} 5=$ ee6afde4dff4b0b0eaf497f58edd39da $>$. Acesso em: 13 out. 2008. doi: 10.1016/S0044-8486(96)01499-8.

JAHAN, P. et al. Improved carp diets based on plant protein sources reduce environmental phosphorus loading. Fisheries Science, v.69, n.2, p.219-225, 2003. Disponível em: <http:/ /www3.interscience.wiley.com/journal/118844129/abstract>. Acesso em: 11 jul. 2008. doi: 10.1046/j.14442906.2003.00611.x.

KIM, M.K. et al. Effect of soybean meal and full-fat soybean for fish meal protein replacement on the growth performance of carp grower. Korean Journal of Animal Nutrition and Feeding, v.21, n.6, p.503-510, 1997.

KRÖGDAHL, A. et al. Carbohydrates in fish nutrition: digestion and absorption in postlarval stages. Aquaculture Nutrition, v.11, n.2, p.103-122, 2005. Disponível em: <http:// www3.interscience. wiley.com/journal/118710585/abstract>. Acesso em: 20 nov. 2008. doi: 10.1111/j.13652095.2004.00327.x.

LUO, L. et al. Partial or total replacement of fishmeal by solvent-extracted cottonseed meal in diets of juvenile rainbow trout (Oncorhynchus mykiss). Aquaculture Nutrition, v.12, n.6, p.418-424, 2006. Disponível em: <http:// www3.interscience.wiley.com/journal/118575583/abstract>. Acesso em: 20 nov. 2008. doi: 10.1111/j.13652095.2006.00443.x.

NANDEESHA, M.C. et al. Further studies on the use of mixed feeding schedules with plant- and animal-based diets for common 
carp Cyprinus carpio (Linnaeus). Aquaculture Research, v.33, n.14, p.1157-1162, 2002. Disponível em: <http:// www3.interscience.wiley.com/journal/118931421/abstract>. Acesso em: 21 nov. 2008 doi: 10.1046/j.13652109.2002.00771.x.

OLVERA-NOVOA, M.A. et al. Sunflower seed meal as a protein source in diets for Tilapia rendalli (Boulanger, 1896) fingerlings. Aquaculture Research, v.33, n.3, p.223-229, 2002. Disponível em: <http://www3.interscience.wiley.com/journal/ 118931453/abstract>. Acesso em: 21 nov. 2008. doi: 10.1046/ j.1365-2109.2002.00666.x.

POLI, C.R.; ARANA, L.V. Qualidade da água em aqüicultura. In: POLI, C.R. et al. Aqüicultura: experiências brasileiras. Florianópolis: Multitarefa, 2003. p.45-72.

TAMASSIA, S.T.J. et al. Ciprinicultura - o modelo de Santa Catarina. In: CYRINO, J.E.P. et al. (Eds.). Tópicos especiais em piscicultura de água doce tropical intensiva. São Paulo: TecArt, 2004. p.267-305.

SANZ, A. et al. Sunflower meal compared with soybean meal as partial substitutes for fish meal in rainbow trout (Oncorhynchus mykiss) diets: protein and energy utilization. Aquaculture, v.128, n.3-4, p.287-300, 1994. Disponível em: <http://

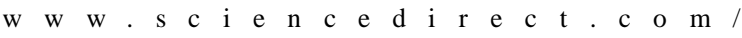
science? ob=ArticleURL\&_udi=B6T4D49NY4V61C\&_user=687 $358 \& \_c o v e r D a t e=12 \% 2 F 15 \% 2 F 1994 \& \_a l i d=920573159 \& \_$rdoc $=$ $15 \& \_f m t=h i g h \& \_o r i g=s e a r c h \& \_c d i=4972 \& \_s o r t=d \& \_d o c a n c h o r=\& v i e$ $\mathrm{w}=\mathrm{c} \& \_\mathrm{ct}=20 \& \_\mathrm{acct}=\mathrm{C} 000037899 \&$ \&version $=1 \&$ \&urlVersion $=0 \&$ userid $=687358 \& \mathrm{md} 5=3 \mathrm{bb} 23430835674 \mathrm{~d} 1 \mathrm{f} 6 \mathrm{e} 3 \mathrm{a} 33 \mathrm{f} 8182 \mathrm{~d} 6 \mathrm{a} 2>$. Acesso em: 21 nov. 2008. doi: 10.1016/0044-8486(94)90318-2.

SOLTAN, M.A. et al. Effect of replacing fish meal by a mixture of different plant protein sources in the Nile tilapia (Oreochromis niloticus) diets. Global Veterinaria, v.37, n.4, p.157-164, 2008. Disponível em: <http://www.idosi.org/gv/ gv2(4)08/3.pdf>. Acesso em: 21 nov. 2008.

WEBSTER, C.D et al. Growth and body composition of channel catfish (Ictalurus punctatus) fed diets containing various percentages of canola meal. Aquaculture, v.150, n.1-2, p.103112, 1997. Disponível em: <http://www.sciencedirect.com/ s c i e n c e ? o b = A r t i c le U R L \&_u d i = B 6 T 4 D 3 R H 6 GNJ 8 \&_user $=687358$ \&_coverDate $=04$ $\% 2 \mathrm{~F} 15 \% 2 \mathrm{~F} 1997 \&$ \&doc $=9 \& \_$fmt $=$high \&_orig=browse\&_srch $=$docinfo $\%$ 23 toc $\% 234972 \% 231997 \% 23998499998 \% 233333 \% 23$ FLP\%23display\%23Volume)\&_cdi=4972\&_sort=d\&_docanchor=\&_ct=13 \&_acct $=$ C $000037899 \& \_$version $=1 \& \_u r l$ version $=0$ \&_userid $=6$ $87358 \& \mathrm{md} 5=7 \mathrm{~cd} 00 \mathrm{a} 4 \mathrm{f} 5 \mathrm{~d} 6 \mathrm{a} 7 \mathrm{f5} 2 \mathrm{df} 4 \mathrm{e} 26538 \mathrm{edf} 1 \mathrm{de} 3>$. Acesso em: 15 set. 2008. doi: 10.1016/S0044-8486(96)01471-8. 